\title{
Os Objetos no Ensino e o Movimento de Tecnologia Educacional no Brasil a Importância da Utilização
}

\author{
Rosilene Batista de Oliveira ${ }^{1}$
}

\begin{abstract}
RESUMO
0 presente artigo discute como a importância da utilização de objetos no ensino é construída, no âmbito do movimento de tecnologia educacional, nas décadas de 60 e 70, no Brasil, considerando as propostas da Psicologia da Aprendizagem, da teoria da comunicação e do enfoque sistêmico, teorias científicas que deram base ao movimento. Com este objetivo, são analisadas obras que tiveram grande repercussão no país, influenciando o ideário pedagógico da época sobre a utilização de recursos tecnológicos no ensino. Com base nos estudos de Michel Foucault, procuramos destacar nos textos analisados as estratégias discursivas que evidenciam e legitimam a utilização dos recursos tecnológicos no ensino, influenciando e alicerçando o movimento de tecnologia educacional. A partir da análise realizada, observamos que o caráter científico da Psicologia da Aprendizagem, da teoria da comunicação e da teoria dos sistemas, bem como o estatuto científico que elas concedem ao saber pedagógico, possibilitam que concepções, propostas e regras sejam aceitas como algo dado, natural, contribuindo para aprofundar a lógica da introdução de objetos no ensino nas décadas de 60 e 70 no Brasil
\end{abstract}

Palavras-chave: Objetos no ensino. Movimento de tecnologia educacional. Teorias.

\section{THE OBJECTS IN TEACHING AND THE MOVEMENT \\ OF EDUCATIONAL TECHNOLOGY IN BRAZIL: \\ The Importance of Using}

\section{ABSTRACT}

This article discusses as the importance of the use of objects in teaching is built within the movement of educational technology in the 1960s and 1970s, considering the learning psychology proposals, communication theory and systems theory, bases scientific given to

1 Professora doutora do corpo docente do Programa de Pós-Graduação em Educação do Centro Universitário Moura Lacerda, em Ribeirão Preto. rosilene.oliveira@mouralacerda.edu.br 
the movement. With this goal, we analyze literatures that had great repercussion in Brazil, influencing the educational ideals of the period on the use of technological resources in teaching. Based on the studies of Michel Foucault, we seek to highlight in the texts analyzed the discursive strategies that highlight and legitimize the use of technological resources in teaching, influencing and basing the movement of educational technology. From the analysis performed, we found that the scientific psychology of learning, communication theory and systems theory and the scientific status that they conceive the pedagogical knowledge, enable that proposals and rules are accepted as something given, natural, contributing to deepen the logic of the introduction of objects in teaching in the 1960s and 1970s in Brazil.

Keywords: Objects in teaching. Movement of educational technology. Theories. 
Ao pensarmos sobre a introdução, apropriação e utilização de objetos e artefatos tecnológicos nas práticas escolares, bem como sobre os significados que eles recebem no processo de ensino e aprendizagem, podemos remeter estudos e investigações a vários momentos da história da educação brasileira nos quais verificamos a importância dada a esses materiais. Entre esses momentos, destacamos as décadas de 1960 e 1970, período em que se intensificam os discursos acerca da utilização de objetos no ensino, no âmbito do movimento de tecnologia educacional no Brasil, que construiu um lugar de destaque para esses materiais, por meio das propostas e teorias que alicerçaram o movimento.

Pesquisas sobre o movimento de tecnologia educacional nos dizem que ele tem suas origens na década de 50, nos Estados Unidos. Vários são os autores que abordam o tema, trazendo uma retrospectiva sobre as origens do movimento, bem como suas principais características e propostas. Autores como Pablo Pons (1998), Maggio (1997), Sancho (1998), Férres (2000) e Oliveira (1996) fazem parte desse grupo de estudiosos sobre a tecnologia educacional. Pablo Pons (1998) e Maggio (1997) destacam que, já na década de 40, em meio à Segunda Guerra Mundial, os Estados Unidos investiram na preparação de seus soldados utilizando-se de instrumentos audiovisuais, como o retroprojetor, influenciando assim a concepção e o desenvolvimento da tecnologia educacional.

Dessa maneira, nesse primeiro momento do movimento, considerando as discussões levantadas por Pablo Pons (1998) e Maggio (1997), percebe-se, de maneira clara, a relação direta que se estabelece nas práticas discursivas que surgem nesse contexto entre tecnologia educacional e a utilização de materiais diversos no ensino. Essa relação é propiciada pela própria concepção de tecnologia que se instaura nesse momento, entendendo-a como a aplicação de conhecimentos científicos na solução de problemas práticos, unindo assim ciência e técnica, conforme Sancho (1998, p. 29) defende neste trecho de seu artigo, ao expor que

esta fusão indissolúvel (e aparentemente indispensável) entre ciência e técnica abre um novo espaço de conhecimento, o da tecnologia como uma técnica que emprega conhecimentos científicos e que por sua vez, fundamenta a 
ciência quando lhe dá uma aplicação prática. A tecnologia configura-se como um corpo de conhecimentos que, além de usar o método científico, cria e/ou transforma processos materiais.

Nos primórdios do movimento de tecnologia educacional, notamos uma tendência de considerar os objetos no ensino como uma tecnologia; o discurso propagado é que ao nos utilizarmos deles estaremos dispondo de conhecimentos técnicos e científicos inerentes à sua produção e utilização, no intuito de solucionarmos um problema: ensinar algo para o aluno. Desse modo, nos processos de produção, apropriação e utilização de objetos no ensino, estão implícitas as noções de técnica e ciência, conjuntamente.

Os objetos, concebidos como tecnologias educacionais, nesta ótica, passam a ter uma função educativa, vinculada a uma finalidade de ensino e às características e peculiaridades do processo educativo. Assim, nesse primeiro momento, a origem da tecnologia educacional estaria ligada aos meios materiais, aos equipamentos audiovisuais, à instrução programada e aos meios de individualização da aprendizagem.

Na década de 50, observa-se uma tendência à alteração das práticas discursivas referentes à tecnologia educacional, marcando uma segunda vertente do movimento, que se baseia no condicionamento operante aplicado ao ensino programado, influenciado pelos estudos de Skinner sobre Psicologia da Aprendizagem, no entanto, não é somente a Psicologia da Aprendizagem que influenciará e ajudará a construir o discurso sobre o que venha a ser a tecnologia educacional. É comum, na literatura sobre o tema, serem destacadas três ciências sociais que contribuíram para o surgimento das propostas da tecnologia educacional: a Psicologia da Aprendizagem, a teoria da comunicação e a teoria dos sistemas. Assim, entende-se que a tecnologia educacional firma-se como uma "ciência ponte" ao servir como ligação entre a técnica e a ciência, abrindo-se às contribuições de outros campos científicos. 
Neste artigo, discutimos as propostas de utilização dos objetos no ensino trazidas por essas teorias científicas: a Psicologia da Aprendizagem, a teoria da comunicação, e a teoria dos sistemas, de maneira a analisar a forma como essas teorias constroem a importância dos objetos no ensino, dada a complexidade dos conceitos e das propostas trazidas por elas ao ideário pedagógico da época.

O conjunto de verdades construídas por essas ciências cria um novo modo de aprender e ensinar por meio dos objetos, neste período histórico, e as práticas discursivas surgidas sinalizam e reiteram as suas contribuições, como podemos verificar nas palavras de Cambi (1999, p. 616), ao comentar sobre as contribuições de Skinner e sua influência sobre o saber acerca da tecnologia educacional e dos objetos no ensino

Com as novas tecnologias educativas, operadas pelas pesquisas do neocomportamentalismo de Skinner e pelo desenvolvimento da computerscience veio se delineando uma centralidade sempre maior atribuídas às máquinas nos processos de ensino e aprendizagem (não mais suportes, mas protagonistas do ensino): como a calculadora, o televisor, os vídeos, os computadores. Desse modo, transformou-se radicalmente o modo de aprender-ensinar: tornou-se mais impessoal, mais controlável, mais microestruturado, mais capaz de autocorreção.

Assim, o principal objetivo deste trabalho é mostrar como os pressupostos teóricos que sustentaram o movimento de tecnologia educacional vão conformando um lugar de destaque para os objetos no ensino, dentro da história da educação brasileira, de maneira que as concepções e significados construídos em torno da sua utilizaçãoincorporam-se ao ideário pedagógico e estendem-se até nossos dias, influenciando também nossa maneira de pensar e utilizar os recursos tecnológicos disponíveis em sala de aula hoje.

As iniciativas e propostas do movimento de tecnologia educacional no Brasil inserem-se em um contexto social, econômico e político marcado pela instalação do regime militar que reorienta o ensino do país. Para Romanelli (1978), podemos definir dois momentos que marcam este período. Num primeiro momento, há a instituição do novo regime e da nova política econômica, voltada para a internalização do capital e a expansão industrial do país. Constata-se, neste momento, de acordo com a autora, uma aceleração do ritmo de crescimento da 
demanda social de educação e são estabelecidos os acordos entre o Ministério da Educação e Cultura (MEC) e a Agency for International Development (AID) - os chamados acordos MEC - Usaid para a assistência técnica e a cooperação financeira para o sistema educacional brasileiro.

O segundo momento é marcado por medidas práticas do governo para enfrentar os problemas educacionais da época, medidas essas que consolidavam a adequação do sistema educacional ao modelo de desenvolvimento econômico que então se intensificava no país.

O "boom econômico", em 1970, originado das três metas econômicasanunciadas pelo então ministro da Fazenda, Delfim Neto, demonstra a ênfase e o desejo do Brasil em participar do mundo desenvolvido e delineia uma conjuntura favorável para o mercado internacional que ocupa o país com as multinacionais e as grandes organizações bancárias, bem como abre espaço para os acordos entre o país e entidades estrangeiras (KOSHIBA; PEREIRA, 1987; SKIDMORE, 1988).

Neste contexto de reformulação das propostas educacionais, diante dos problemas e necessidades impostas por mudanças políticas e econômicas, delineiam-se também enunciados sobre a introdução e utilização de objetos variados no ensino como formas de inovação e modernização das práticas escolares usadas até então (FISCARELLI, 2009).

No âmbito das propostas educacionais vinculadas à tecnologia existente na época aplicada à educação, os objetos e materiais transformam-se em objetos discursivos, recebem um lugar específico e definido no interior dessas propostas.

Os estudos foucaultianos, tomados como fundamentação teórica do presente trabalho, contribuem para pensarmos sobre as práticas construídas em torno dos objetos no ensino, incluindo as práticas discursivas, as quais constroem saberes e significados sobre os mesmos, conformando modos possíveis de concebê-los, de falar sobre eles e de usá-los em sala de aula. Exige-se uma nova concepção de pressupostos teóricos, distanciando-se da noção tradicional de teoria, na qual supõe-se que ela descreveria e descobriria o "real": um "real" preexistente, ideal, desde sempre ali inscrito, onde paira a verdade. De acordo com Veiga-Neto (2006), em seu artigo Na oficina de Foucault, a preocupação 
com o "real", com a origem da verdade, não paira sobre a atmosfera que envolve as questões e considerações propostas por Michel Foucault, ao longo de sua obra. Pelo contrário, Veiga-Neto (p. 87) afirma que "Foucault não está aí para nos dizer as verdades sobre as coisas, mas sim para nos ajudar a compreender de que maneiras, por quais caminhos, tudo aquilo que se considera verdade tornou-se um dia verdadeiro".

Assim, consideramos que as propostas e concepções do movimento de tecnologia educacional, nas décadas de 60 e 70, são construídas em meio ao contexto político, social e econômico da época, e estão impregnadas de estratégias e motivações que tentam legitimar o discurso sobre a importância da utilização de recursos tecnológicos no ensino. Nossa intenção, então, é conhecer como a movimento de tecnologia educacional, por meio de seus pressupostos teóricos e científicos, tornou verdadeiro para a época o discurso que propagava a importância de se utilizar a televisão; o rádio; o cinema educativo; o retroprojetor, os materiais impressos, como o flanelógrafo, o cartaz, o quadro mural; e outros tantos recursos tecnológicos disponíveis para o ensino nesse período histórico.

Com base nessas considerações, procuramos mostrar e descrever a partir de quais regras e quais estratégias, construídas e firmadas pela Psicologia da Aprendizagem, pela teoria da comunicação e pela teoria dos sistemas, ciências que alicerçaram e estruturam as concepções e propostas do movimento de tecnologia educacional, pôde-se colocar os objetos num discurso pedagógico, cujo caráter de cientificidade viabiliza a sua utilização na sala de aula. Com esse objetivo, apoiamo-nos nos trabalhos de alguns autores, estrangeiros e brasileiros, como fonte bibliográfica, os quais discutiram em seus estudos as principais contribuições dessas três Ciências para a introdução da tecnologia na educação.

O corpus selecionado como fonte para o desenvolvimento deste trabalho foram livros editados e publicados nas décadas de 60 e 70, os quais tiveram grande repercussão no Brasil, influenciando o ideário pedagógico da época sobre a utilização de recursos tecnológicos no ensino. Seus autores foram citados e referenciados diversas vezes na literatura sobre o tema tecnologia educacional, e seus estudos e propostas serviram de base teórica para outros trabalhos científicos realizados na época. Desse modo, escolhemos o livro de Burrhus F. Skinner, Tecnologia do Ensino, para conhecermos e compreendermos suas propostas para 
a utilização dos objetos, no âmbito da Psicologia da Aprendizagem. Também selecionamos os estudos de Berlo (1978), Dance (1973) e Maser (1975), autores estrangeiros que foram utilizados como referência bibliográfica sobre a teoria da comunicação, de maneira bastante recorrente no Brasil. No que concerne à teoria dos sistemas, os trabalhos de Bertallanffy (1973) e Churchman (1972) que aparecem de maneira recorrentes nas referências bibliográficas de textos que discutem o movimento de tecnologia educacional no Brasil, nas décadas de 60 e 70, foram tomados para a nossa discussão, considerando os principais pressupostos teóricos trazidos pela teoria geral do sistema e a utilização de objetos no ensino.

Buscando conhecer como a importância da utilização de objetos no ensino é construída por meio dessas teorias científicas, procuramos conhecer as estratégias discursivas que evidenciam e legitimam a utilização de recursos tecnológicos no ensino, influenciando e alicerçando o movimento de tecnologia educacional. Dessa forma, a partir da relação estabelecida entre as palavras escritas utilizadas e os sentidos e significados que elas sugerem, procuramos traçar os caminhos que o discurso científico conduz o pensamento sobre os objetos no ensino.

Com base nos estudos de Michel Foucault, entendemos o discurso como modos de pensar sobre o mundo e as coisas, que se materializa na palavra dita ou escrita, constituindo-nos como sujeitos. A intenção então é conhecer como o discurso que propaga a importância da utilização de objetos no ensino, vistos como tecnologia educacional, legitima-se numa dada época da história da educação brasileira e é aceito como verdade, ganhando um status científico por meio das teorias científicas que o sustentam.

\section{A Psicologia da Aprendizagem - os objetos como reforço}

A tecnologia educacional tornou-se uma realidade para a Psicologia ao delinear-se o campo da Psicologia da Educação, reconhecida como uma "ciência ponte" entre os estudos psicológicos e sua aplicação educacional. Assim, as teorias psicológicas passaram a ser consideradas constituintes dos pilares 
sobre os quais se apoia a tecnologia educacional, dividindo-se em duas vertentes: as teorias psicológicas associacionistas e as teorias psicológicas cognitivas (DIB, 1974). Entre os estudiosos associacionistas destacam-se no discurso as propostas e métodos de aprendizagem de Skinner, como grandes contribuições ao movimento de tecnologia educacional.

Os estudos de Skinner voltam-se ao desenvolvimento e comportamento da criança; ou seja, preocupam-se com as respostas que a criança dá a determinados estímulos ao longo de suas várias idades, relacionando esse comportamento com o meio ambiente no qual ela está inserida. Nesse contexto, Skinner (1972) deixa bem claro o papel do professor: ele é o transmissor do conhecimento, o fecundador de ideias, o moldador de comportamentos. O ensino é visto como uma construção: a construção do comportamento desejado do aluno pelo professor. A escola, ao ser o locus do ensino formal, deve possibilitar contingências de reforço, compostas por três variáveis: a ocasião em que o comportamento ocorre, o próprio comportamento e, as consequências do comportamento.

Assim, o comportamento do aluno deve ser controlado; ele deve ser conhecido e reforçado pelo professor. Vendo o reforço como uma grande necessidade para se atingir o comportamento desejado do aluno, Skinner (1972) critica a pouca frequência do reforço nas salas de aula, o que, para ele, causa a ineficiência no ensino de determinadas matérias que exigem muitos exercícios, como a Aritmética, e propõe a utilização de reforçadores, tanto os naturais como os mecânicos. Quanto aos reforçadores, Skinner (1972, p.19) mostra a importância deles, neste trecho de seu livro, destacando os objetos manipuláveis de forma natural pela criança, sem nenhuma propriedade aversiva.

As crianças brincam durante horas com brinquedos mecânicos, tintas, tesouras e papel, chocalhos e tambores, quebra-cabeças - em poucas palavras com quase tudo que as informa das modificações substanciais que elas provocam no ambiente e que seja razoavelmente isento de propriedades aversivas.

Skinner (1972) propõe também que para se atingir padrões extremamente complexos de comportamento, deve-se subdividir um grande número de passos e o reforço será utilizado na realização de cada um desses passos. Para o autor, 
esses requisitos resolvem o problema de manter o comportamento desejado e fortalecido, controlando-o durante todo o processo de ensino e aprendizagem. Partindo-se dessas considerações, a ação docente torna-se ineficiente para um ensino dirigido a vários alunos numa mesma sala. $\mathrm{O}$ discurso legitima que fica quase inviável contar somente com a figura do professor para o controle individualizado do comportamento de diferentes alunos. Desta forma, Skinner (1972) propõe uma maneira de programação do ensino, de modo a reforçar o comportamento educacional desejado, por meio de recursos instrumentais que podem ser programados eficazmente - as máquinas de ensinar. O discurso científico de Skinner (1972) considera a introdução de recursos audiovisuais no ensino como um caminho para a melhoria da educação. Para o autor, "os recursos audiovisuais suplementam e podem mesmo suplantar aulas, demonstrações e livros didáticos" (p. 27), pois ao nos utilizarmos deles estaremos suprindo uma função do professor, uma vez que esses recursos podem apresentar as matérias, tornando-as claras e interessantes aos alunos.

Apesar dessa grande importância dada às máquinas de ensinar, ou seja, aos objetos, Skinner (1972) salienta que essas são somente equipamentos para uso dos professores e que não os substituirão. Sua função, quanto ao papel docente, é a de poupar esforço e tempo do professor, delegando-lhe outras funções que são próprias de um ser humano e que não podem ser exercidas pelas máquinas. Observa-se, no entanto, o lugar de destaque que os objetos recebem nas propostas psicológicas de Skinner (1972) quando o autor menciona que "algum tipo de artefato é necessário para arranjar as contingências sutis de reforço, requeridas para uma aprendizagem ótima, se cada aluno merecer atenção individual" (p. 53).

As propostas de Skinner para o processo de ensino e aprendizagem dão um sentido à utilização de objetos no ensino, além da figura do professor. $\mathrm{O}$ sentido é estabelecido no discurso pela criação da necessidade de se modificar e controlar o comportamento do aluno e procurar uma forma ótima para isso. Essa forma ótima é encontrada na utilização de determinados objetos, como as máquinas de ensinar, as quais podem ao mesmo tempo controlar e ensinar um determinado comportamento, individualmente. $\mathrm{O}$ discurso enunciado, então, 
forma um saber, um conhecimento sobre os objetos no ensino, assim como Foucault (2000) reitera que o saber se liga a um discurso. Podemos considerar que, a partir desse discurso, o saber instituído é aquele que legitima não bastar apenas a figura do professor, pois a ela deve associar-se a introdução de um objeto no ensino capaz de reforçar, controlar, motivar e alcançar resultados mais eficazes ao processo de ensino e aprendizagem.

A Psicologia da Aprendizagem, por meio de um estatuto científico, constrói necessidades educacionais como estratégias discursivas, que induz a viabilidade e incentivo à utilização de qualquer tipo de objeto no ensino. Criam-se necessidades quanto ao conhecimento do tipo de resposta que o aluno poderá dar a um determinado estímulo, quanto à modulação de um tipo de comportamento e quanto ao controle individual do desenvolvimento cognitivo de cada aluno. Além dessas necessidades, outras são delineadas quando se estabelecem discursivamente as teorias cognitivistas. Valoriza-se, então, os sentidos, a percepção, a experiência no processo de ensino-aprendizagem, e os objetos adentram fortemente no discurso por meio das concepções e propostas educacionais que enfatizam a sua importância no processo educativo. Esses saberes construídos levam o ideário pedagógico a pensar positivamente a utilização de objetos no ensino.

\section{A Teoria da Comunicação - os objetos como canais}

Os estudos sobre teoria da comunicação constituíram também um ponto de referência forte para o campo da tecnologia educacional. Estudos como de Shannon e Weaver (Matemática), Schramm (Sociologia), Jakobson (Linguística) e Maletzke (Psicologia da Comunicação) trouxeram para a tecnologia educacional um conjunto de pressupostos teóricos e metodológicos que influenciaram suas propostas de aplicação e, particularmente, a introdução e utilização de objetos no ensino. Estudos como os de David Berlo, Frank Dance e Siegfried Maser, autores estrangeiros, foram utilizados como referência bibliográfica sobre a teoria da comunicação, de maneira bastante recorrente no Brasil. Podem então 
ser considerados como a base para as discussões no país a respeito da teoria da comunicação e sua influência sobre o movimento de tecnologia educacional. Esses três autores, apesar de definirem de forma diferente o conceito de comunicação, de maneira complementar, a entendem como um processo, ou seja, uma atividade humana que apresenta mudanças contínuas no tempo e sofre influências de fatores que a cercam, conforme as palavras de Berlo (1979, p. 34) mostram, ao discutir a comunicação entendida como processo.

A teoria da comunicação reflete esse ponto de vista de processo. O teórico da comunicação rejeita a possibilidade de que a natureza consista em acontecimentos ou ingredientes separáveis de todos os demais acontecimentos. Alega que não se pode falar em o começo ou o fim da comunicação, nem dizer que determinada ideia veio de uma fonte específica, que a comunicação ocorre apenas numa direção.

Ao entender a comunicação como processo, estabelecem-se os componentes desse processo; ou seja, os ingredientes que participam do processo comunicativo. Assim, a comunicação é, de maneira geral, a troca ou permuta de ideias que se processa entre um emissor, que envia a mensagem, e um receptor, que a recebe. A conexão entre emissor e receptor é feita por um canal, no qual o elemento primordial é o meio que torna possível o transporte da mensagem (MASER, 1975).

O discurso científico estabelece que o emissor, a partir de um repertório constituído de elementos diversos, como letras, palavras, números, cores, sons, e por um sistema de regras, destinado a ordenar esses elementos, codifica a mensagem que chega até o receptor, o qual deverá decodificá-las utilizando o mesmo repertório de elementos e sistemas de regras que o emissor utilizou. Só assim, a mensagem será compreendida.

Alguns autores, como Santos (1980), mostram que a proliferação de objetos no ensino, como os recursos audiovisuais, tem como principal sustentação e suporte teórico a teoria da comunicação. Assim, podemos afirmar que a teoria da comunicação legitima um lugar de destaque aos objetos na educação, considerada como uma ação comunicativa. O discurso científico preconiza os objetos no processo comunicativo como o canal, o meio pelo qual a mensagem é 
transportada do emissor para o receptor. Dessa forma, por meio desse discurso, a utilização de um meio físico torna-se essencial para que haja comunicação, para que ocorra aprendizagem. A definição de canal, dada por diferentes estudiosos da teoria da comunicação, deixa bem claro a importância desses objetos no processo comunicativo. Ao considerar a comunicação como essencial e importante para a sobrevivência humana, para a troca e construção de conhecimentos e informações no âmbito das relações sociais, tornando natural e evidente a importância da utilização de instrumentos que melhorem o processo comunicativo, o discurso enunciado pela teoria da comunicação estabelece significados e produz subjetividades em torno da utilização de objetos na educação. As práticas discursivas construídas dentro deste estatuto científico, moldam, guiam e afetam a conduta e a maneira de pensar dos sujeitos educacionais da época.

Percebemos então que a relação entre a utilização de um determinado objeto e a efetividade de resultados esperados, numa atividade humana como a comunicação, parece ficar estabelecida e legitimada cientificamente, dentro do discurso enunciado, pelos pressupostos teóricos que sustentam o ato de se comunicar. Se o discurso científico entende e coloca como verdade que a efetividade da comunicação depende do canal; ou seja, do meio físico pelo qual a mensagem será enviada a um possível decodificador, torna-se quase óbvia a importância da utilização de qualquer objeto como canal comunicativo, como instrumento de comunicação e educação.

Todos os componentes do processo comunicativo são importantes para essa efetivação, porém, de acordo com o discurso, de nada adianta o emissor codificar da melhor maneira a mensagem se não tiver um meio para enviá-la até seu alvo. Dessa forma, a utilização do meio, no discurso da teoria da comunicação, é imprescindível nesse processo, mas não diminui sua dependência de outros componentes que integram o processo comunicativo, pois acredita-se que não se pode tomar decisões sobre o canal se antes não decidirmos qual será a mensagem enviada, nem tampouco decidirmos o canal antes de escolhermos o código que será utilizado. Estabelece-se então a relação que o objeto deve ter com outros componentes do ato educativo, tais como: conteúdo, objetivo, avaliação, etc. Perceber o ensino, a situação de aprendizagem, como um processo comunicativo 
parece ter sido uma das principais concepções surgidas a partir da influência do discurso científico da teoria da comunicação sobre o discurso pedagógico, a partir da década de 50, e que adentra o discurso pedagógico deste período.

Segundo Berlo (1975, p. 80), para que haja aprendizagem é imprescindível a existência de um estímulo, definido pelo autor como "qualquer coisa que uma pessoa pode receber através de um dos sentidos". O estímulo deve ser percebido pelo indivíduo, que deve responder-lhe, reagir a ele, percebê-lo e também interpretá-lo. Assim, entende-se que a aprendizagem se concretiza por meio dos sentidos humanos: tato, olfato, visão, audição e paladar. Esses sentidos devem ser estimulados por meio de instrumentos, canais físicos, pelos quais a mensagem educativa é transmitida ao aluno. Mais do que isso, o discurso legitima que a aprendizagem somente ocorrerá quando a resposta a um determinado estímulo for efetivada e tornar-se algo habitual. É neste ponto que os objetos, os meios, os recursos audiovisuais, os materiais didáticos, os recursos de ensino, enfim, os artefatos eletrônicos ou não, recebem um sentido dentro do discurso, uma coerência, e entram no processo educativo como algo importante.

A teoria da comunicação motiva à criação de saberes em torno dos objetos no ensino, incita a falar sobre eles, motiva a colocá-los em discurso por meio de um conjunto de regras, normas, verdades que constroem um lugar para eles no ideário pedagógico brasileiro, principalmente nas décadas de 60 e 70, quando se observa uma preocupação e intensificação da introdução de objetos no ensino.

\section{A Teoria Geral dos Sistemas ou Enfoque Sistêmico: os objetos como recursos}

A teoria geral dos sistemas ou enfoque sistêmico foi formulada nos anos de 1930, mostrando uma nova maneira de se pensar o funcionamento da sociedade, diferente da existente no século 19 e primeira metade do século 20 , a qual via o mundo como um caos. Assim, a nova concepção de mundo o vê como uma organização e marca a emergência de um feixe de novas disciplinas, entre elas a teoria geral dos sistemas (BERTALANFFY, 1973). 
Churchman (1972) define sistemas como um conjunto de partes coordenadas para realizar um conjunto de finalidades. Bertalanffy (1973) vê um sistema como um complexo de elementos em interação. As duas definições evidenciam a necessidade de uma interação organizada entre os componentes de um conjunto para que haja um sistema. Esta interação deve ser movida por uma finalidade, um objetivo comum, e todos os componentes do sistema, direcionam-se a agir com a intenção de atingir este objetivo, criando assim um enfoque sistêmico. Partindo dessas considerações, Churchman (1972) expõe em seu trabalho quais os recursos de que uma sociedade dispõe para pensar melhor sobre a sua organização e sobre a maneira de resolver os seus problemas. Considera como exemplo de educação, o sistema educacional. Nele há vários tipos de recursos (pessoas, dinheiro, equipamentos) que entram no sistema, os inputs, e os serviços que saem como resultados das ações desenvolvidas dentro do sistema educacional, os out-puts. Assim, por meio desse discurso tomado como científico e verdadeiro dentro do movimento de tecnologia educacional, as concepções sistêmicas passam a ser aplicáveis no processo educacional como forma de racionalizar as ações educativas e controlar as variáveis que podem incidir sobre o processo de ensino e aprendizagem. A ênfase dada à redução de custos, não somente quanto aos gastos financeiros, mas também quanto ao tempo gasto para a obtenção de resultados positivos, bem como a quantidade de recursos físicos e humanos, deixa evidente uma filosofia baseada na eficiência, na concepção de que existe o "melhor modo" de se realizar uma determinada tarefa dentro do sistema educacional (FISCARELLI, 2009).

Tendo como foco o processo de ensino e aprendizagem, os objetos passam a ser considerados como in-puts do sistema educacional, sendo vistos como o "melhor modo", como os recursos importantes para que o sistema atinja sua finalidade educativa. O discurso científico construído pela teoria geral dos sistemas induz a considerar os objetos como entradas no sistema e que têm uma função particular: auxiliar os professores na tarefa de transmitir o conhecimento ao aluno, de maneira que esses saiam do sistema educacional aptos a viverem na sociedade da época e participarem da sua construção (FISCARELLI, 2009). 
A utilização de um objeto no ensino é vista como algo que pode diminuir o tempo gasto para a assimilação dos conteúdos, reduzir a imprescindibilidade do professor como transmissor de conhecimentos, racionalizar as práticas dentro da sala de aula e garantir a almejada qualidade do ensino, nas décadas de 60 e 70, no âmbito do movimento de tecnologia educacional no país.

A proposta da teoria geral dos sistemas orienta os olhares em torno da introdução e utilização de objetos no ensino, e adota estratégias que permitem aos sujeitos educacionais, principalmente aos professores, conceberem esses objetos como importantes e essenciais ao processo de ensino e aprendizagem, construindo assim um lugar de destaque e uma função primordial para os eles dentro do sistema educacional da época.

\section{Considerações Finais}

As teorias aqui destacadas adentraram o saber pedagógico das décadas de 60 e 70 no Brasil, influenciando e alicerçando o movimento de tecnologia educacional, de forma a nortear concepções e propostas de como a tecnologia poderia ser efetivada na educação. Por meio de suas propostas, essas teorias elevam a importância dos objetos no processo educativo. O caráter científico de cada uma delas possibilita que concepções, propostas e regras sejam incorporadas ao saber pedagógico, bem como aproveitadas e apropriadas às propostas do movimento de tecnologia educacional que objetivava legitimar-se no momento, num contexto político que buscava o desenvolvimento econômico do país e concebia a educação como um meio de alcançar este fim. Os objetos são concebidos como instrumentos capazes de melhorar o processo educativo, tornando-o mais eficiente e eficaz; no entanto, a figura do professor, como mediador desse processo, também se mostra importante, pois é visto como efetivador e mediador da relação entre aluno e objeto, levando-nos a refletir sobre a materialidade dos objetos e a importância da ação educativa docente que recai sobre eles.

Observamos que o discurso científico, enunciado pelas teorias que dão suporte às propostas do movimento de tecnologia educacional, usa a criação de necessidades, a ênfase às potencialidades dos objetos, a busca pela qualidade 
do ensino, o papel do professor como efetivador da utilização desses objetos, a preocupação com uma educação concernente ao desenvolvimento econômico do país, como estratégias para moldar um lugar importante para os objetos na educação brasileira nas décadas de 60 e 70 no Brasil

As discussões apresentadas a partir da análise realizada levam-nos pensarmos e discutirmos a introdução de objetos no ensino hoje, principalmente os provenientes das novas tecnologias, no que concerne a sua importância. Assim, mostra-se relevante não refletir somente sobre a sua utilização em sala de aula, mas também sobre as maneiras como esta importância foi construída ao longo dos anos pelo ideário pedagógico e a relação que este ideário mantém com o saber científico, construindo para os objetos significados que nortearam e que ainda norteiam muitas das práticas pedagógicas existentes em nossas escolas.

Estes saberes têm construído e legitimado verdades acerca da utilização de objetos no ensino, influenciando a maneira como concebemos a prática docente diante dessa utilização, a qualidade da educação oferecida com ou sem a utilização de objetos tecnológicos no ensino, bem como a necessidade de formação docente direcionada à utilização de novas tecnologias. Sendo vistos como importantes e essenciais ao processo de ensino e aprendizagem, pelas teorias destacadas, os objetos no ensino ganharam significados dentro do movimento de tecnologia educacional iniciado no Brasil nas décadas de $60 \mathrm{e}$ 70; e muitos desses significados estão presentes no nosso ideário pedagógico atual. Compreender, no entanto, a importância dos objetos no ensino deve perpassar não somente por conhecer como esta importância é construída por meio de teorias científicas evidenciadas neste trabalho, mas também conhecer os significados e sentidos dados aos objetos no espaço escolar, no cotidiano da sala de aula, pelos professores e alunos que dela fazem parte, considerando a escola um espaço também de produção de saberes. A importância dos objetos no ensino também é construída a partir da maneira como os professores e alunos deles se apropriam e os utilizam, construindo suas verdades acerca desses objetos, verdades essas que nascem da experiência diária, da tentativa e erro e da maneira como ressignificam esses objetos no interior da escola. 


\section{Referências}

BERLO, D. K. O processo da comunicação: introdução à teoria e à prática. São Paulo: Martins Fontes, 1975.

BERTALANFFY, L. Von. Teoria Geral dos Sistemas. Petrópolis: Editora Vozes, 1973

CAMBI, F. História da pedagogia. São Paulo: Ed. da Unesp, 1999.

CHURCHMAN, C. West. Introdução à teoria dos sistemas. Petrópolis: Editora Vozes, 1972.

DANCE, F. E. (Org.). Teoria da comunicação humana. São Paulo: Cultrix, 1973.

DIB, C. Z. Tecnologia da educação e suas aplicações à aprendizagem de Física. São Paulo: Livraria Editora Pioneira, 1974.

FÉRRES, J. Pedagogia dos meios audiovisuais e pedagogia com os meios audiovisuais. In: SANCHO, Juana Maria (Org.). Para uma tecnologia educacional. Porto Alegre: ArtMed, 1998. p.127-155.

FISCARELLI, R.B.O. A construção do saber sobre a utilização de objetos no ensino brasileiro. 2009. Tese (Doutorado) - Universidade Paulista Julio de Mesquita Filho, Faculdade de Ciências e Letras de Araraquara -FCLAr, 2009.

FOUCAULT, M. As palavras e as coisas. São Paulo: Martins Fontes, 2000.

KOSHIBA, L.; PEREIRA, D. M. F. História do Brasil. São Paulo: Atual, 1987.

MAGGIO, M. O campo da tecnologia educacional: algumas propostas para sua reconceitualização. In: LITWIN, Edith (Org.). Tecnologia educacional. Porto Alegre: Artes Médicas, 1997. p.12 -21.

MASER, S. Fundamentos de teoria geral da comunicação. São Paulo: EPU; Edusp, 1975.

OLIVEIRA, H.J.C. Os meios audiovisuais na escola portuguesa. Braga: Universidade do Minho; Instituto de Ciências da Educação, 1996. p. 122-127.

PABLO PONS, J. Visões e conceitos sobre a tecnologia educacional. In: SANCHO, Juana Maria (Org.). Para uma tecnologia educacional. Porto Alegre: ArtMed, 1998. p.50-71.

ROMANELLI, O. História da Educação no Brasil (1930-1973). Petrópolis: Editora Vozes, 1978.

SANCHO, J. M. A tecnologia: um modo de transformar o mundo carregado de ambivalência. In: SANCHO, Juana Maria (Org.). Para uma tecnologia educacional. Porto Alegre: ArtMed, 1998. p. 23-49.

SANTOS, L. L. C. P. O mito da eficiência no ensino: estudo crítico da tecnologia educacional. 1980. Dissertação (Mestrado) - Universidade Federal de São Carlos, 1980. 
SKIDMORE, T. Brasil: de Getúlio a Castelo. Rio de Janeiro: Paz e Terra, 1988.

SKINNER, B.F. Tecnologia do ensino. São Paulo: Ed. Herder; Ed. da Universidade de São Paulo, 1972.

VEIGA-NETO, A. Na oficina de Foucault. In: GONDRA, José; KOHAN, Walter (Org.). Foucault 80 anos. Belo Horizonte: Autêntica, 2006. p. 79-92.

Recebido em: 1\%/2016

Aceito em: 21/11/2016 